\title{
Erratum: The role of church youth in the transformation agenda of South African cities
}

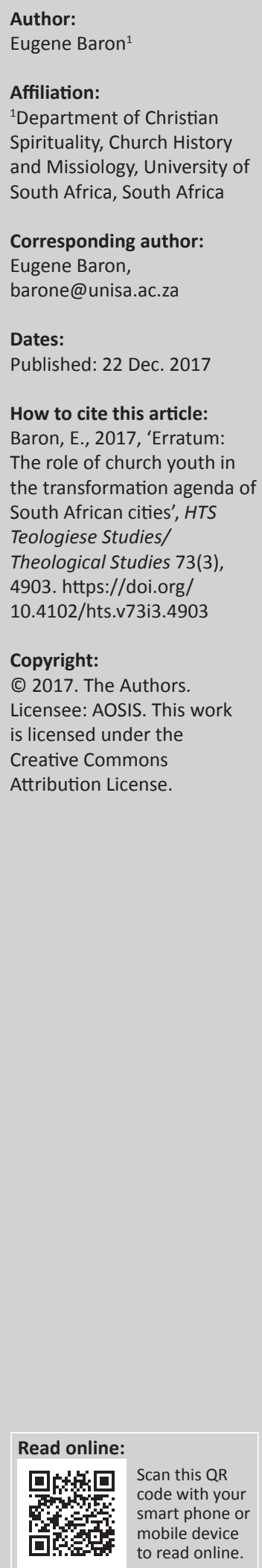

In the version of this article initially published, the incorrect funding information was acknowledged in the note. The note is hereby corrected and updated as: 'This article forms part of a collaborative research project entitled "Religious innovation and competition amidst urban social change: A Pretoria case study." The project was funded by the Templeton Foundation as part of an African-wide enquiry on "Christianity and social change in contemporary Africa." The project is also a sub-theme of the "Faith in the City" research project, hosted by the Centre for Contextual Ministry in the Faculty of Theology, University of Pretoria'. This correction does not alter the study's findings of significance or the overall interpretation of the study results. The editor apologises for any inconvenience caused. 